\title{
GRUPOS FOCAIS COMO RECURSO DE CONSTRUÇÃO DO LÚDICO NA EDUCAÇÃOAMBIENTAL: RELATO DE UMA EXPERIÊNCIA ABORDANDO A PERCEPÇÃO DE RISCOS
}

EINLOFT, Carlos Joaquim. Administrador. Mestrando do Programa de Pós-graduação em Extensão Rural da Universidade Federal de Viçosa. Av. P.H. Rolfs, s/n - Campus - Cep: 36.570-000 - Viçosa, MG.

E-mail: carlos.einloft@ufv.br.

FERREIRA NETO, José Ambrósio. Doutor em Desenvolvimento, Agricultura e Sociedade, Professor Associado III do Programa de Pós-graduação em Extensão Rural da Universidade Federal de Viçosa. Av. P.H. Rolfs, s/n - Campus - Cep: 36.570-000 - Viçosa, MG. E-mail: ambrosio@ufv.br.

\section{RESUMO}

O enfrentamento dos problemas socioambientais do mundo hodierno passa, necessariamente, por processos educativos, dentre os quais a educação ambiental. Dentre muitas ferramentas, os jogos se destacam por seu caráter lúdico que permite a abordagem e assimilação de conteúdos, mesmo os mais complexos, pelo seu caráter divertido. Entretanto, para a superação de modelos de construção de práticas educativas que agem de forma etnocêntrica, invasiva, "de cima para baixo", é preciso que se considere uma concepção educativa abrangente, que permita a construção do conhecimento "com o sujeito" e não "para o sujeito". Um dos caminhos para superação desse modelo está, portanto, atrelado a processos participativos que envolvam o usuário final do instrumental em sua dinâmica de construção, isto é, uma metodologia capaz de acolher o sujeito no processo de conhecimento. Dessa forma, este artigo apresenta os grupos focais como recurso de construção do lúdico na educação ambiental, investindo, nesse sentido, no relato de uma experiência de pesquisa em que o tema principal foi a percepção de riscos, sejam eles ambientais, tecnológicos ou sociais. Com o propósito de superar uma concepção de educação ambiental meramente instrumentalizadora, de caráter heteronômico e mecanicista, apresentamos uma contribuição para o debate sobre a utilização de metodologias participativas na pesquisa social, discutindo os grupos focais no processo de elaboração de um instrumento lúdico de construção coletiva e polissêmica, que resultou na construção de um jogo com dupla natureza de construção social do conhecimento, sendo a primeira o processo mesmo de elaboração do jogo, e a segunda, o caráter catalisador de debates capaz de permitir a construção social do conhecimento no encontro de múltiplas subjetividades na aplicação prática da dinâmica.

Palavras-chave: Grupos focais; Educação ambiental; Percepção do risco.

FOCAL GROUPS AS A RESOURCE OF CONSTRUCTION OF THE LUDIC IN ENVIRONMENTAL EDUCATION: AN EXPERIENCE REPORT DEALING WITH THE RISK PERCEPTION

\begin{abstract}
Educational processes, among them environmental education, are necessary to face the socioenvironmental problems in today's world. Among all the pedagogical resources, games stand out for their playful nature, allowing to approach and assimilate contents, even the most complex ones, as a result of their funnycharacteristic. However, to overcome the models of educational practices based on ethnocentric, invasive way, it is necessary to consider a comprehensive educational concept which allows the construction of knowledge "with the subject" and not "for the subject". One way to overcome this model is linked to a participatory process involving the final users of the instrumental in its dynamic of construction, that is, a methodology which is able to include the subject in his/her knowledge process. So, this paper presents the focal groups as a resource in the construction of
\end{abstract}


playful environmental education, presenting a report of a research experience in which the main theme was the perceptions of environmental, technological and social risks. In order to overcome a conception of a merely mechanicistic environmental education, we offer a contribution to the debate on the participative methodologies in social research, discussing the focal groups in the process of elaboration of a ludic instrument, polissemic and collectively built, which has resulted in the construction of a game with a double nature in its social construction of knowledge, being the first one, the process of game elaboration itself and the second, the catalyser character of debates, allowing the social construction of knowledge in the confluence of the multiple subjectivities involved in the practical application of the dynamics.

KEYwORDs: Focal groups; Environmental education; Risk perception.

\section{INTRODUÇÃo}

As complexas questões socioambientais evidenciadas em escala planetária estão associadas ao modelo de desenvolvimento adotado e aos padrões de consumo atuais. Considerando-se que o enfrentamento dessa problemática e dos riscos decorrentes da modernidade industrial é dependente dos processos educativos, o desenvolvimento de metodologias voltadas para a educação ambiental, ou nela ancoradas, podem constituir-se em estratégias eficientes em processos de ressignificação e mudança na percepção do meio em que se está inserido, assim como das múltiplas dimensões que o tornam complexo. Segundo FraPaleo (2010a) a complexidade refere-se à interveniência e concorrência de múltiplos fatores na formação de um determinado risco.

Instrumentos lúdicos construídos por meio de práticas participativas, quando bem desenvolvidos e aplicados com objetivos definidos, permitem que os temas sejam abordados de forma reflexiva (GIDDENS et al., 1997). Isto é, ultrapassando os limites do ensino tradicional e potencializando discussões, podem ajudar a estabelecer uma relação dos problemas socioambientais daquela realidade específica que está sendo trabalhada, e mesmo estratégias para enfrentá-los, seja os anulando ou apenas atenuando seus efeitos negativos.

Não se trata, portanto, de produzir um instrumental que responda a uma determinada demanda objetiva ou a algum problema imediato, mas sim de possibilitar a ressignificação da relação do sujeito como seu meio, visando, emúltima análise, a sua autonomia, entendida aqui como a capacidade ou o poder de atuar segundo sua própria norma ou regra determinante de suas decisões (FREIRE, 1996; COELHO, 2005).

Há uma grande incoerência em algumas ações educativas que pretendem auxiliar em processos de ressignificação da relação do sujeito com o ambiente quando, na prática, as ações instrumentais se traduzem em mero atendimento de demandas realizadas, somente, por sujeitos especialistas que estão de fora da realidade objetiva onde pretendem atuar, que no mais das vezes agem de forma etnocêntrica, invasiva, e até mesmo violentando aspectos relacionados aos modos de vida locais. É possível superar esse modelo? Este artigo argumenta que, para a superação desse modelo de construção de práticas de educação ambiental, é preciso que se considere uma concepção educativa abrangente, como a educação defendida por Paulo Freire, da construção do conhecimento "como sujeito" e não "para o sujeito". Defendemos aqui que umdos caminhos para superação desse modelo está, portanto, atrelado a processos participativos que tragam o usuário final do instrumental para a sua dinâmica de construção, isto é, na medida em que a própria elaboração do lúdico encontrar uma metodologia capaz de acolher o sujeito no processo.

Dentre uma gama de possibilidades, os grupos focais emergem como uma das técnicas capazes de envolver o sujeito nesse processo de construção. Para Minayoet et al. (2010) a técnica do grupo focal constitui-se em um tipo de entrevista ou conversa em grupos pequenos, homogêneos, uma forma planejada para se obter informações relativas a um tema específico.

$\mathrm{Na}$ exposição das próprias ideias, crenças, impressões, conceitos, representações, os participantes 
têm a possibilidade de confrontar seus pontos de vista no debate entre todos, sem nenhuma preocupação em chegar a consensos. O que se procura aí é o próprio confronto das ideias que pode, no mais das vezes, produzir um resultado muito maior do que o somatório de entrevistas separadas. O debate permite o amadurecimento de uma opinião, mudanças de ideias, de posicionamento, o exame de cada questão por diversos ângulos, considerando mesmo a multiplicidade de posicionamentos de que cada pessoa pode ser capaz de produzir em função de seus valores, crenças e opiniões socialmente construídos. Esses posicionamentos surgem da visão que cada indivíduo possui da realidade, que, para Bourdieu (1989), está relacionada com a quantidade de capitais sociais, econômicos, culturais e simbólicos que este indivíduo é capaz de mobilizar.

Este artigo tem como objetivo discutir, portanto, os grupos focais como recurso de construção do lúdico na educação ambiental, investindo, nesse sentido, no relato de uma experiência de pesquisa em que o tema principal foi a percepção de riscos socioambientais. Com o propósito de superar uma concepção de educação ambientalmeramente instrumentalizadora, de caráter heteronômico, etnocêntrico, invasivo e mecanicista, apresentamos uma contribuição para o debate sobre a utilização de metodologias participativas na pesquisa social, discutindo os grupos focais no processo de elaboração de um instrumento lúdico de construção coletiva e polissêmica. O que trazemos como novidade é a criação de um jogo de tabuleiro de elaboração coletiva através da técnica do grupo focal, utilizando aqui os preceitos da educação ambiental crítica, isto é, o envolvimento do sujeito no processo e o estímulo à sua autonomia e capacidade de reflexão crítica. Um dos preceitos da educação ambiental crítica, que sustentam a sua escolha como opção teórica, é a sua capacidade de estimular os sujeitos envolvidos no processo educativo a relacionar os problemas ambientais com o contexto social ao qual pertencem, formando uma consciência crítica da sociedade e das relações sociais (LOUREIRO, 2005), absolutamente necessária para a irrupção de processos autônomos de empoderamento sobre seu entorno, tomada de decisão e mesmo a construção de um novo olhar.

\section{EduCAÇão AMBIENTAL E PRÁTICAS LúdiCAS \\ Educação ambiental}

Do surgimento da ideia em 1972, na Conferência de Estocolmo, até a sua consolidação no Rio de Janeiro na Eco 92, a educação ambiental passou por uma constante e gradativa modificação em sua essência. Naquele primeiro momento foi apontada como estratégia de informação dirigidaa atores sociais individuais e coletivos, atribuindo-lhes, já aí, sua parcela de responsabilidade no combate à degradação ambiental. A Declaração sobre o Ambiente Humano, documento final resultante dessa Conferência, se por um lado advoga a necessidade do avanço do desenvolvimento no sentido de crescimento econômico, por outro e, pela primeira vez, apresentou a necessidade de que este desenvolvimento seja aliado à preservação do meio ambiente, e para tal, estabelece princípios gerais de ação.

No Encontro de Belgrado, em 1975, falou-se numa ética global de indivíduos e sociedade, e em 1977, na então União Soviética, na Conferência de Tbilisi, na Georgia, o foco foi a própria educação ambiental, que recebeu uma "função capital" de dilatação da compreensão dos problemas ambientais por parte dos indivíduos, assim como a necessidade do seu envolvimento ativo no processo de resolução dos problemas ambientais por meio de uma postura crítica, proativa e emancipadora.

Em 1992, no Rio de Janeiro, a Rio 92 modificou a forma de pensar o tema desenvolvimento, adjetivando-o como sustentável. Deslocou os seres humanos para uma posição central para este desenvolvimento, atribuindo-lhes "direito a uma vida saudável e produtiva, em harmonia com a natureza". E, para tanto, apresentou-se a necessidade da disponibilidade de informação à população, bem como a sua participação nos processos de tomada de decisão. Vemos aqui uma proposta que busca alterar valores e condutas, e mesmo a estrutura de poder vigente em níveis local e regional.

Em âmbito nacional, a Política Nacional de 
Educação Ambiental trouxe uma definição que se apoia na construção de valores, conhecimentos, habilidades, dentre outros, necessários para a sustentabilidade no longo prazo com qualidade de vida. Coloca, entretanto, essas ações objetivas nas mãos do ator social, que, a partir de um determinado processo de educação ambiental, seria capaz de promover mudanças em sua realidade imediata, melhorar o seu meio e, consequentemente, a sua própria vida. E, ainda, dentre os objetivos da educação ambiental está "o desenvolvimento de uma compreensão integrada do meio ambiente em suas múltiplas e complexas relações, envolvendo aspectos ecológicos, psicológicos, legais, políticos, sociais, econômicos, científicos, culturais e éticos" (LEI 9.795, 1999:2). Essa totalidade não dissocia o homem do seu meio, mas relaciona-o a todas as suas dimensões, integrando natureza e sociedade, inclusive sob a perspectiva de que o homem é sujeito e objeto de transformações ocorridas em ambas, pelas inter-relações por ele mediadas.

Para Dias (2006), a educação ambiental permite às pessoas aprender como funciona o ambiente, como dele dependemos, e com ele interagimos, promovendo a sua sustentabilidade. $\mathrm{O}$ autor atrela, portanto, a dependência da vida humana ao sistema natural, isto é, aos recursos naturais e aos serviços ambientais, além da necessidade de compreender o seu funcionamento, visando a sua sustentabilidade através da educação ambiental.

Assim, uma proposta que envolva educação ambiental deve contemplar o alcance da "sinergia social", termo cunhado por Ruth Benedict (FADIMAN, 1979 in BROTTO, 1999) e que se refere ao grau de cooperação e harmonia interpessoal numa sociedade, relacionado à ação cooperativa dos elementos, que resultaria num efeito global maior do que todos os elementos somados separadamente. Assim, temos um panorama de ampliação do raio de ação da educação ambiental, superando a visão estrita e heteronômica de um conteúdo a ser aprendido em livros ou cartilhas, para uma leitura e percepção de mundo que se constrói através da prática cotidiana.

Por outro lado, Lopes e Tenório (2011) alertam para a tendência reducionista que grassa nas práticas de educação ambiental, isto é, ambiente significando natureza, e problema ambiental significando problema ecológico, derivando dessa visão dois graves problemas: o desprezo pelas dimensões políticas, éticas e culturais da questão, e a utilização de metodologias não participativas. No primeiro problema, ignora-se o cenário onde se dão os modos de vida em todas as esferas da vida social pública ou particular, e, no segundo, impõe-se de cima para baixo, ignorando a possibilidade de criação dialógica da atividade de intervenção social. Ambos os problemas levantados se referem à não localização da dimensão humana no centro dos projetos de intervenção social, uma prática heteronômica, isto é, sentidos e orientações construídos externamente à realidade objetiva do público a ser envolvido, e etnocêntrica. $\mathrm{O}$ conhecimento não se estende de uma fonte que o domina para uma que o ignora, mas se constitui nas relações homem-mundo, relações de transformação, se aperfeiçoando na problematização crítica das relações (FREIRE, 2007).

Dessa forma, a educação ambiental pode ser um veículo de construção e compartilhamento de saberes acerca do meio em que um dado grupo social se insere, por meio da ressignificação dos elementos constituintes do seu entorno e da problematização das múltiplas dimensões da vida social. Isto é, a educação ambiental não visa resolver problemas objetivos imediatos, mas estimular a capacidade de problematização para que surjam comportamentos autônomos que busquem as soluções para se evitar ou mitigar determinadas situaçõesproblemas, dentre as quais figuram os diferentes tipos de riscos e vulnerabilidades. É justamente por meio dessa capacidade autônoma de problematização, de ressignificação, de construção de valores sociais, conhecimentos, habilidades, atitudes e competências que o indivíduo poderá vir a ser capaz de identificar potenciais fatores de ameaça a seu modo de vida, à reprodução de suas condições de sobrevivência e de se tornar capaz de fazer frente aos desafios que o meio lhe impõe. Em suma, a educação ambiental deverá possibilitar ao indivíduo a construção de sua autonomia e criticidade frente ao meio em que está inserido. 


\section{O lúdico como instrumento para a educação ambiental}

Dentre as várias ferramentas de que se dispõe na educação ambiental, os jogos se destacam por seu caráter lúdico, isto é, pela diversão e também pela possibilidade de troca de experiências, pelo estímulo ao espírito de cooperação e pela sua importância no desenvolvimento da criatividade e da capacidade de concentração. Esses fatores facilitam a assimilação de conceitos, mesmo os mais complexos, como os que se relacionam à educação, em especial a ambiental, e ao uso racional e sustentável dos recursos naturais em favor do desenvolvimento sustentável.

Segundo Rojas (s/d), a ludicidade é uma necessidade do ser humano em qualquer idade e não pode ser vista apenas como diversão. O desenvolvimento do aspecto lúdico facilita a aprendizagem, $o$ desenvolvimento pessoal, sociale cultural, colabora para uma boa saúde mental, prepara para um estado interior fértil, facilita os processos de socialização, comunicação, expressão e construção do conhecimento. Brotto (1999) trabalha essa construção do conhecimento de forma coletiva ou cooperativa e propõe uma interessante comparação entre situações opostas, na qual se evidencia claramente a vantagem da situação cooperativa sobre a competitiva na construção coletiva em todos os aspectos abordados (Quadro 1).

\begin{tabular}{|l|l|}
\hline Situação cooperativa & Situação competitiva \\
\hline $\begin{array}{l}\text { Percebem que o atingimento dos objetivos é, em } \\
\text { parte, consequência da ação de outros membros }\end{array}$ & $\begin{array}{l}\text { Percebem que o atingimento de seus objetivos é } \\
\text { incompatível com a obtenção dos objetivos dos } \\
\text { demais }\end{array}$ \\
\hline São mais sensíveis às solicitações dos outros & São menos sensíveis às solicitações dos outros \\
\hline Ajudam-se mutuamente com frequência & Ajudam-se mutuamente com menor frequência \\
\hline $\begin{array}{l}\text { Há maior homogeneidade na quantidade de } \\
\text { contribuições e participantes }\end{array}$ & $\begin{array}{l}\text { Há menor homogeneidade na quantidade de } \\
\text { contribuições e participantes }\end{array}$ \\
\hline
\end{tabular}

Quadro 1 - Comparação entre situação cooperativa e competitiva nos jogos. Fonte: Adaptado de BROTTO (1999).

Concordamos com Brotto (1999), quando afirma que o jogo, ou a prática lúdica de qualquer natureza, deve ser capaz de desenvolver as "coopetências", termo por ele cunhado que significa "competências compartilhadas", fundamentais para a chamada construção dialógica do conhecimento, para as práticas coletivas de cooperação e participação, para o desenvolvimento da autonomia e até, emúltima análise, para a melhoria das condições de vida das pessoas.

Dessa forma, por meio de dinâmicas relativamente simples, acessíveis a diferentes extratos etários e níveis de educação formal, é possível alcançar resultados surpreendentes no que se refere à assimilação de conhecimentos, ao aprofundamento de discussões sobre a intervenção e interação do homem com a natureza e seu meio, e a busca de soluções exequíveis para os problemas que se thes são apresentados. Muito mais do que a abordagem individual de problemas práticos imediatos, trata-se de estimular o desenvolvimento da capacidade de problematização dessas situações objetivas, por meio de um enfoque emancipador, que permita a modificação de determinados padrões de comportamento, valores sociais e culturais. A dinâmica lúdica participativa permite aos envolvidos perceberem de forma mais consistente a maneira pela qual o conhecimento teórico encontra lugar no mundo real, somando-se ao seu conhecimento tradicional, tanto na apreensão de uma 
dada situação ou realidade, quanto na busca de soluções factíveis, pois esses sujeitos conseguem perceber-se como parte de um todo maior e entender como se tornam por ele responsáveis e capazes de modificá-lo. Para Sachs (2000), o casamento do saber prático sobre seu próprio meio com o conhecimento acadêmico é o ponto de partida para o estabelecimento de estratégias de ação e enfrentamento dos problemas que se lhes apresentam.

As práticas participativas, de forma geral, e os jogos, em particular, estimulamo ser humano em vários sentidos quando se prioriza seu aspecto cooperativo, estimulando a participação de todos em torno de um objetivo comum, facilitando a interação e a emissão de opiniões de forma livre, mesmo por parte daqueles que não se sentem à vontade para fazê-lo normalmente. Nesse sentido, esperamos que a utilização de metodologias lúdicas como ferramenta para educação ambiental possa gerar esses estímulos para a participação, para a construção coletiva e dialógica da percepção dos riscos e que essa informação possa, efetivamente, se traduzir em conhecimento capaz de melhorar a relação do homem com o meio onde se insere. Assim, um processo que propicie o envolvimento do sujeito na elaboração de um instrumento lúdico de construção coletiva emerge como alternativa às práticas heteronômicas de produção de instrumentais normalmente encontrados na educação ambiental.

\section{O TEMA EM FOCO}

Dentre a multiplicidade de temas discutidos nas questões ambientais, um assunto emergente é o risco, característica indelével da modernidade. A compreensão sobre o meio ambiente, suas complexidades e interações com a atividade humana, por meio da informação adquirida e assimilada, pode se constituir tanto em um fator determinante para a sustentabilidade ambiental das atividades socioeconômicas no longo prazo, quanto da percepção da própria exposição e vulnerabilidade a diferentes riscos.

Dessa forma, o enfrentamento e a mitigação dos eventuais efeitos negativos de determinado risco ao qual se está exposto se tornam mais exequíveis à medida que se conta com maior volume de informação, do qual é possível extrair conhecimento sobre a presença do homem no meio e dos efeitos desta interrelação intrínseca, papel que pode ser cumprido por boas práticas de educação ambiental. Assim, a disponibilidade de informações em quantidade e qualidade pode permitir o conhecimento acerca da paisagem de riscos da qual se faz parte.

A sociedade está imersa num contexto de incertezas, mudanças e complexidade. Aincerteza é a incapacidade de predizer com exatidão o curso dos acontecimentos futuros, como a disponibilidade de recursos naturais e serviços ambientais suficientes, as mudanças dos ambientes naturais, as mudanças ambientais induzidas pela ação humana e mesmo sobre os processos sociais. As mudanças se referem às condições ambientais, socioeconômicas e políticas do mundo hodierno, em constante transformação. Acomplexidade diz respeito à interveniência e concorrência de múltiplos fatores na formação de um determinado risco, podendo a própria complexidade se constituir num risco em si mesma. Nesse contexto de incertezas, mudanças e complexidades são necessárias a renovação e a circulação constante de informação para informar ou reforçar a memória de risco das populações, no sentido de se criar um estado de atenção permanente capaz de atenuar os efeitos negativos da eventual objetivação de algum desastre potencial.

Assim, o problema emergente é a própria percepção de risco, pela inexatidão intrínseca das informações a ele relacionadas - uma vez que toda predição é baseada em modelos que são apenas aproximações à realidade -, bemcomo pela desatualização e mesmo pela completa ausência de qualquer informação.

Temos aí dois extremos: por um lado, um volume cada vez maior de informação disponível, e, por outro, o não acesso a essas informações por parte significativa da sociedade. O que se vê é, portanto, uma grande quantidade de informação que não necessariamente se traduz em conhecimento para a tomada de decisão por parte dos decisores políticos ou executores de 
políticas públicas, aumentando, dessa forma, a vulnerabilidade a determinado risco que uma parcela da sociedade pode estar exposta.

Entretanto, a informação de risco, catalisada em conhecimento por meio da educação ambiental, pode também gerar na população um aumento significativo da percepção da própria exposição e vulnerabilidade ao risco. Por outro lado, o aumento do conhecimento sobre a existência e exposição a determinados riscos não os elimina e nem elimina a exposição, mas pode ajudar a promover uma mudança postural que atenue os seus efeitos negativos através de medidas preventivas que diminuam a vulnerabilidade. E, nesse sentido, as práticas de educação ambiental podem explicitar a exposição e auxiliar na diminuição da vulnerabilidade.

\section{Risco}

Segundo o sociólogo alemão Ulrich Beck, o risco é uma antecipação de um evento de consequências negativas, mas não o evento em si mesmo (BECK, 2008a; 2008b). É, portanto, uma virtualidade, um "que vir" que pode ser manejado, gerido e planejado para antecipar ou mitigar os seus eventuais efeitos danosos. $\mathrm{O}$ autor assevera que o risco está associado às decisões humanas. Os riscos "resultam da transformação de inseguranças e perigos em decisões" (BECK, 2008b:157). E, nesse sentido, há distinções importantes entre os termos risco e perigo: o primeiro, como adrede mencionado, está relacionado à decisão, à intervenção humana, oriunda de algum processo de tomada de decisão (inundações em áreas urbanizadas, poluição, ataques terroristas, dentre outros); já o segundo está relacionado com causas que estão além do controle humano (eventos naturais como terremotos, erupções vulcânicas, dentre outros) (LUHMANN, 1990 in BRÜSEKE, 2007). Giddens (1991) diferencia risco de perigo pela consciência da ameaça que o indivíduo tem por uma determinada linha de ação. O risco pressupõe o perigo e não a consciência do perigo (GIDDENS, 1991). Isto é, quando assume um "risco calculado", o indivíduo está consciente do perigo enquanto ameaça a um determinado resultado esperado.
Outro conceito central da obra de Ulrich Beck é "sociedade do risco", que ele define como uma sociedade que se ocupa em debater, prevenir e administrar os riscos que ela mesma produziu (BECK, 2008a). A "sociedade do risco" é toda uma nova ordem mundial global, socioeconômica e mesmo de modificações no nível pessoal, gerada a partir da combinação dos riscos ecológicos, químicos, nucleares, genéticos e econômicos (GUIVANT, 2001). No mundo moderno, industrializado e globalizado, o ponto de comunhão entre todos é, justamente, o risco, ou como assevera Milton Santos, citado por Zaniratoet et al. (2008), os riscos são produtos históricos e resultantes de ações e omissões humanas e expressão do desenvolvimento das forças produtivas e do período técnico-científico-informacional e, portanto, são o resultado de uma construção social.

Os riscos, como virtualidades de eventos de consequências negativas, precisam, portanto, ser previstos, visualizados, avaliados e, sobretudo, informados à sociedade, principalmente àquele grupo que é objeto da ameaça em questão para que possa percebê-lo, dimensioná-lo e avaliar suas possibilidades de ação e reação.

\section{Percepção de risco e informação}

A percepção é uma sensação pessoal, subjetiva e inerente ao indivíduo (CASPARRI et al., 2011), que varia de acordo com a visão que a pessoa possui do ambiente, combinada com os capitais que é capaz de mobilizar. Portanto, ela é única e variável de acordo com o contexto socioeconômico e cultural, o local e o tempo no qual o indivíduo ou grupo social está inserido. Para Douglas e Wildavsky (2012), os riscos devem ser abordados sob uma perspectiva cultural, uma vez que, entendidas as dinâmicas de convívio com o risco e de sua prevenção, estratégias específicas podem ser construídas através de cada contexto cultural.

Uma dada situação de risco não é, também, garantia de que a população por ele ameaçada o perceba, mesmo com ele convivendo cotidianamente, uma vez que pode estar exposta ou vulnerável a um risco mesmo sem saber de sua existência. Isto é, a situação de risco 
não é capaz, sozinha, de gerar informação e conhecimento de uma potencial ameaça que poderia redundar numa conjugação de esforços para mitigá-la ou atenuar seus efeitos. Zaniratoet et al. (2008) afirmam que a percepção do risco se dá de forma subjetiva e técnica, isto é, subjetivamente, por meio de sua construção social e, tecnicamente, pelos especialistas que o diagnosticame também por aqueles que comunicam seus potenciais efeitos ao público.

Dados quantitativos, informações institucionais, conhecimento da área e seus elementos constituintes, memória midiática e história oral de desastres são alguns dos fatores que alimentam o estoque de informações necessárias para a percepção dos riscos. A importância do conhecimento pode ser avaliada pela ponderação de Beck (2008b) ao afirmar que, quanto menos se sabe sobre um determinado risco, mais se está vulnerável a ele, o que pode causar consequências imprevisíveis. E, ainda, que enquanto não se adquirir consciência de sua ameaça, o risco não pode ser objeto de investigação, planejamento e política. A percepção do risco é, portanto, importante tanto para o grupo social por ele afetado, quanto para os decisores políticos responsáveis por aquela região.

O conhecimento dos riscos, dos fatores desencadeantes, intervenientes ou concorrentes que o tornam complexo, impõe-se, portanto, como uma necessidade. A informação é o veículo desse conhecimento e deve ser contínua, porque, segundo FraPaleo (2010b), a modificação de percepção e atitude dos cidadãos e dos responsáveis políticos locais é um processo que deve reforçar-se continuamente para que seja efetivo e duradouro.

\section{Exposição e vulnerabilidade}

Beck (2008a) aponta o nível de exposição de risco como a principal desigualdade da sociedade moderna. Isto é, determinados atores sociais podem mobilizar capitais de uma maneira tal que minimizem para si a exposição ao risco em detrimento da maximização para outrem (BECK, 2008a), escolhendo para si uma alimentação e hábitos mais saudáveis, uma moradia mais segura, acesso a informação em quantidade e qualidade. Por outro lado, às classes economicamente menos favorecidas resta uma maior vulnerabilidade a diferentes riscos, como a água contaminada, a insegurança pública, a incerteza quanto ao futuro, o não acesso à educação, a renda insuficiente, a insegurança alimentar, dentre outros.

A vulnerabilidade está relacionada coma fragilidade do sistema e sua incapacidade de superar os eventuais efeitos negativos de uma crise (ZANIRATO et al., 2008), isto é, está na sua gestão. Enquanto a exposição pode chegar a ser "democrática", por expor a todos, a vulnerabilidade está relacionada com a capacidade de gerir o risco. E para gerir os riscos é preciso o manejo adequado das informações sobre a paisagem de risco, tanto aquelas informações técnicas advindas do ambiente acadêmico, quanto dos saberes locais relacionados àquele contexto onde se reproduz as condições de existência e sobrevivência, à cultura e gênero de vida, as suas desigualdades, vantagens e potencialidades.

A convivência e a exposição ao risco são condições inerentes à sociedade moderna, e nem sempre podem ser evitadas por uma série de fatores contextuais e socioeconômicos. Entretanto, a percepção do risco pode ser um fator determinante para a capacidade de atuar de maneira preventiva e defensiva atenuando a vulnerabilidade aos efeitos negativos de um eventual desastre.

A ludicidade, como forma de abordagem na educação ambiental, articulada com a informação de risco, pode gerar um aumento na sua percepção e visualização, por meio da compreensão e entendimento dos riscos em sua complexidade, naturalizando a capacidade de problematização dos atores. Isto é, justamente o aspecto lúdico, divertido, da atividade, pode potencializar a capacidade de apreensão de informações de risco, que, eventualmente, pode gerar a combinação de esforços dos atores envolvidos no sentido de mitigar ou atenuar seus efeitos negativos.

\section{O RELATO DA EXPERIÊNCIA}

\section{A construção dos grupos focais}

A escolha da metodologia grupo focal se deu em 
função da sua característica básica de permitir a livre expressão dos participantes, em caráter qualitativo e com maior aprofundamento dos temas abordados (NETO, 2002). Adefinição dos sujeitos da pesquisa se deu em razão da sua vivência ou experiência com situações de risco, fator que os homogeneíza, bem como em razão de sua multiplicidade no que diz respeito à formação e origem de cada um, o que torna o grupo bastante heterogêneo, aumentado o leque de possibilidades. Isto é, os perfis definidos foram de pessoas que mobilizam conjuntos de capitais sociais, culturais e econômicos diferentes entre si, mas todos com alguma vivência em situação de risco direta ou indireta.

O grupo que se consolidou e esteve presente em todas as reuniões se compôs de 10 pessoas, reunindo uma considerável multiplicidade de perfis. Na maior parte dos casos, os perfis eram compostos por pessoas com vivências de risco múltiplas, pela sua própria multiplicidade identitária. Como exemplo, citamos um agente do sistema prisional que, antes de ocupar esse cargo, havia sido agente de saúde do programa de controle de endemias da Prefeitura Municipal de Viçosa. Além disso, exerce papel de liderança comunitária em seu bairro e, nos momentos de folga de sua atividade laboral principal, atua como eletricista autônomo para complementar sua renda.

Segundo Neto (2002), o número de participantes está ligado diretamente ao objetivo da realização do grupo focal, isto é, se o objetivo é conseguir o maior número possível de opiniões sobre um determinado tema, deve-se optar por um número maior de participantes; se, por outro lado, a intenção for um maior aprofundamento das questões apresentadas, deve-se optar por um número menor, para que todos tenham a oportunidade de expor suas ideias, refletir sobre o confronto das opiniões e que tudo isso posso acontecer dentro do período de tempo estipulado para a reunião.

Não existem fórmulas para a definição do número de reuniões a serem realizadas nem tampouco nenhuma relação de amostragem. Este número deverá surgir em função da evolução das reuniões em relação aos objetivos propostos, isto é, devem ser realizadas tantas reuniões quantas forem necessárias para que se esgotem satisfatoriamente todos os temas a serem abordados. Assim, foram realizadas cinco entrevistas em local que garantiu o conforto a todos os envolvidos em função da sua estrutura física e, também, para garantir a qualidade das gravações.

O roteiro do debate foi construído em função dos objetivos da pesquisa, através da pontuação dos temas a serem discutidos, utilizando-se algumas questõeschave, assim como alguns desdobramentos para o seu aprofundamento. Nas primeiras quatro entrevistas foram abordadas diretamente as questões relacionadas ao risco, por exemplo: o que é, sua relação causal com múltiplos fatores, como a situação financeira, saúde, segurança pública, condições de trabalho; os porquês de as pessoas viverem em áreas de risco; como as pessoas e os grupos percebem os riscos; fatores que podem evidenciar ou mascarar a presença de um risco; comportamentos individuais e coletivos frente aos riscos; estratégias de convivência com os riscos; por que alguns riscos são aceitos e outros rejeitados, dentre outras. Na última reunião foi feita uma breve exposição sobre a educação ambiental, no sentido de relacionar os riscos sobre essa perspectiva, e em seguida foram abordadas questões diretamente relacionadas à informação e compartilhamento de saberes sobre os temas; como deveriam ser organizadas, e quais os tipos de informações que deveriam constar no jogo, a sua dinâmica, dentre outros.

Dessa forma, foi possível a prospecção, a partir do diálogo e do debate mediado entre os participantes, das informações relacionadas aos temas elencados. Os temas propostos pelo mediador foram expostos à apreciação do grupo, sem buscar a convergência das opiniões, sendo permitido, e até estimulado, o conflito de ideias, no sentido de buscar a multiplicidade de opiniões, para uma eventual reflexão mais rica sobre cada temática abordada. Ou ainda, no dizer de Minayo (2010),

O que se procura é exatamente a cartografia das opiniões, argumentos e pontos de vistas, 
concordantes ou conflituosos, críticos ou resignados. O grupo permite, ainda, o aprofundamento das influências recíprocas entre os falantes, ou seja, a reflexividade das opiniões (MINAYO, 2010: 173-174).

Assim, foram realizados debates dos quais emergiram dados subjetivos acerca das realidades vivenciadas pelos sujeitos da pesquisa, que constituem representações dessas mesmas realidades, formadas por "ideias, crenças, maneiras de pensar, opiniões, pensamentos, maneiras de sentir, maneiras de atuar, condutas, projeções para o futuro, razões conscientes ou inconscientes de determinadas atitudes e comportamentos" (MINAYO, 2012:65). Dessa forma, e uma vez mais, ressalta-se que não se pretende contar opiniões, palavras ou expressões utilizadas, mas sim a exploração do sentido do conteúdo expresso em palavras pelos sujeitos participantes. Daí a opção da análise de conteúdo, definida por Bardin (2011) como

Um conjunto de técnicas de análise das comunicações visando obter por procedimentos sistemáticos e objetivos de descrição do conteúdo das mensagens indicadores (quantitativos ou não) que permitam a inferência de conhecimentos relativos às condições de produção/recepção (variáveis inferidas) dessas mensagens (BARDIN, 2011:48).

Isto é, a análise de conteúdo constitui-se em uma espécie de decodificação para além dos conteúdos manifestos em palavras. O que se busca é a compreensão dos significados das falas, que está muito além do mero alcance descritivo da mensagem, para atingir, mediante inferência, uma interpretação mais profunda (GOMES, 2011).

\section{Subsídios do grupo focal na construção do instrumento lúdico}

Como já afirmado, a pesquisa não tencionou contar respostas, ou quantificar quaisquer dados, mas, através de depoimentos que se referem à realidade que cada um dos participantes vivencia em seu dia a dia, explorar o conjunto de opiniões, crenças e representações que cada um possui sobre o risco em si, e outros temas a ele relacionados.

Na última reunião, na qual convergiram todas as impressões, representações, experiências e relatos de vivências pessoais a respeito da temática do risco, assim como suas estratégias de convivência com os riscos, eventuais tentativas de evitá-los, mitigá-los ou atenuar os seus potenciais efeitos negativos, emergiram os relatos de caráter normativo de como deveria ser a dinâmica do jogo. Isto é, os subsídios para a elaboração de um instrumento lúdico que tenha por premissa a capacidade de auxiliar outras pessoas que venham a utilizá-lo a perceber os riscos do seu entorno através de um olhar "diferenciado". Assim, o debate terminou por evoluir para o próprio processo de construção e compartilhamento de saberes.

Os entrevistados tiveram, então, a oportunidade de discutir acerca do que deveria ser o jogo em termos de sua própria dinâmica de jogabilidade, seu formato, suas regras e outros elementos constituintes a ele relacionados. Além disso, toda a discussão e depoimentos acerca da convivência com diversas situações de risco foram utilizados para subsidiar as questões abordadas no jogo. Dessa forma, prevaleceram as ideias consensuais surgidas do debate mediado, dentre as quais: o jogo deve gerar discussão e, portanto, promover o compartilhamento do conhecimento construído socialmente; o jogo deve trazer conhecimento científico e popular; a união dessas duas ideias iniciais deveria resultar num processo de ressignificação. Sem dúvidas a técnica do grupo focal foi determinante para a eleição desses princípios para o jogo, uma vez que os entrevistados convergiram na ideia de que as discussões promovidas nas diversas reuniões promoveram a apreensão de novos conhecimentos para todos os presentes e este mesmo processo, se aplicado ao jogo, facilitaria também a apreensão do conteúdo abordado pelo próprio tabuleiro, assim como o conhecimento compartilhado, por parte dos seus usuários. Para além da mera apreensão de um novo conhecimento, emerge daí 
também a percepção de um novo olhar sobre aquilo que já se conhece, uma vez que as vivências compartilhadas, os enfoques distintos sobre questões comuns, iluminam ângulos diferentes de uma mesma questão, revelando novas perspectivas.

A partir das discussões iniciais sobre riscos, os entrevistados perceberam que estes são infinitos, uma vez que sua percepção é construída socialmente, ligada a aspectos culturais relativos a cada realidade de onde se origina cada indivíduo. Torna-se, dessa forma, imperativo considerar que não se podem listar riscos para dá-los a conhecer a outrem a partir de, digamos, uma lista. O que se pode mudar, em verdade, é o olhar que se tem, ou sua capacidade de enxergar a mesma coisa sob diferentes ângulos.

Destacamos algumas falas que subsidiaram a elaboração do jogo, sendo a primeira, e talvez uma das mais fortes assertivas sobre a relevância da utilização dos grupos focais se deu quando de uma pergunta a respeito da dinâmica do jogo a se construir, sobre o que poderia ser feito para sensibilizar o olhar dos jogadores para que passassem a ressignificar o seu entorno e, eventualmente, perceber os riscos:

Entrevistada 2: Eu acho que com isso aqui que a gente tá fazendo [aponta para o grupo]. Você [as pessoas] dá a sua opinião e a gente já vai começando a ver, né! Eu não sei, na minha maneira de pensar, é isso tudo que você falou. Aí a gente começa a abrir novos horizontes para outras coisas.

E logo a seguir, completa este mesmo raciocínio:

Entrevistada 2: A gente vê no jornal, ou num debate igual esse aqui, a gente vai começando a ter outros olhares pras coisas também. Você entendeu? Eu acredito muito nisso! Você que vive no seu mundo, naquele mundinho é diferente. Quando você começa a conversar com pessoas, os assuntos, debater outras coisas, a Entrevistada 3 tava falando da comunidade, você [o mediador] tava falando da campanha do quilo, você vai abrindo novos horizontes, vai vendo a realidade que é muito diferente. Aí com isso você já vai abrindo a sua mente pra certas coisas que você achava que isso também não podia...

No momento em que procuramos subsídios para a construção do instrumento lúdico para a percepção de risco, a Entrevistada 2 explicita sua opinião de que o debate que estávamos realizando naquele momento era o que estava, justamente, provocando este efeito nela. Ao expressar-se em termos de "sair daquele mundinho" e "abrir novos horizontes", ela se refere explicitamente às possibilidades de construção de um novo olhar para o mundo exterior, para as diversas situações, no contato com outras pessoas, através da construção social de um conhecimento compartilhado. Para Freire (2006), as relações homem-mundo são constitutivas do conhecimento em qualquer fase do desenvolvimento. Isto é, o homem em seu mundo, relacionando-se com as situações constrói talvez não apenas a base, como todo o corpo de seu conhecimento. E é essa relação entre os sujeitos da pesquisa para a ressignificação do meio, presente na própria realização da reunião, que a Entrevistada 2 diz ser necessária no jogo, para ser capaz de, também, permitir a ressignificação dos temas e a apropriação de conhecimentos e saberes socialmente construídos e compartilhados.

E o entrevistado 1 continua o raciocínio sobre a necessidade da discussão como forma de construção negociada do conhecimento, uma vez mais, em razão do que vivenciou na sua própria experiência de participar das reuniões. A seguir a transcrição não apenas de uma fala, mas de um trecho bastante eloquente sobre a dinâmica do jogo, isto é, da possibilidade de se chegar a conclusões, a respostas, ou mesmo a outras perguntas:

Entrevistado 1: Eu acho que o que a Entrevistada 2 falou é muito interessante, $e$ eu pensei que no fim ela ia colocar, o jogo tem que trazer a discussão! jogo tem que 
estimular a discussão entre quem tá ali, entre os participantes.

Mediador: Ou seja...

Entrevistado 3: O jogo não vai trazer soluções! Mediador: ...o jogo não vai ensinar, ele vai estimular a pessoa a chegar à conclusão!

Entrevistada 3: É!

Entrevistado 4: Exatamente!

Entrevistada 2: A gente vai aprendendo! Aí a gente vai só aumentando o conhecimento!

Discutindo a respeito das possibilidades contidas na troca de saberes, na experiência do compartilhamento dos conhecimentos construídos, vem à tona uma representação social bastante comum sobre aprender com os erros, não apenas aqueles que se cometem no curso da própria vida, mas na experiência acumulada de outras pessoas ou grupos sociais. Dessa forma, a ideia que surge é que o jogo deverá explorar os conhecimentos, as vivências e impressões de seus jogadores como parte da sua própria dinâmica. $\mathrm{O}$ trecho a seguir explicita essas ideias:

Entrevistado 3: Sim, mas a gente não precisa só aprender com os erros da gente! Claro que a gente aprende com os erros da gente. Mas também podemos aprender com os erros dos outros. E para isso precisa ter diálogo. Aí é a diferença né! Esse instrumento [o jogo] vai provocar esse diálogo...

Mediador: E a reflexão!

Entrevistado 3: Exatamente! Porque você vai conversar com o outro para conhecer um pouco da experiência do outro, que é aonde você pode tirar aprendizado de alguma coisa. Mediador: Quer dizer, então o jogo poderia ter, os participantes poderiam exemplificar situações de risco?

Entrevistado 3: Sim! Sim!

Mediador: Além da discussão?

Entrevistado 3: Sim!

O Entrevistado 3 sugere, portanto, que o jogo, além de estimular a discussão entre os participantes visando à construção do conhecimento, que os participantes venham a contribuir com relatos pessoais a serem compartilhados para a formação de um conhecimento comum. O Entrevistado 3 se convence de que esta estratégia de exemplificação funcionará para o jogo exatamente por ter funcionado no curso das reuniões do grupo focal. Várias foram as manifestações acerca do aprendizado que foi possível apreender nos dias das reuniões.

A ideia da discussão tornou-se um ponto-chave para o jogo, como o é para o próprio grupo focal, uma vez que poderá propiciar a reflexão sobre os temas e a eventual autonomia para a percepção de fatos, circunstâncias ou mesmo conhecimentos que não se conseguiriam sozinho. Assim como os participantes do grupo focal não são meros espectadores do processo nem objetos da pesquisa, mas sujeitos parceiros na produção coletiva de um conhecimento, os jogadores envolvidos também deverão ser considerados sob essa ótica. Deverão se apoiar num ponto de partida do tabuleiro e, a partir daí, discutir, reflexivamente, as questões propostas no sentido de gerar o próprio conhecimento.

Ainda sobre a dinâmica do jogo, questionados se achavam que o jogo deveria estimular a competição ou a cooperação, foram feitas diversas considerações, como a seguir:

Entrevistado 3: Eu não vou querer falar das minhas experiências, pensando que eu vou acabar beneficiando você não!

Entrevistado 4: É a questão do tênis e do frescobol né. No tênis cada um quer jogar forte... Isso, mas no frescobol cada um tem que ajudar o outro. Quanto mais caprichada [a bola]você jogar pro outro, mais o jogo continua. Eu acho que a questão do jogo é nesse sentido. É um ajudar mais o outro...

Entrevistado 1: Faz sentido! Então você não vai ser.. né, com a articulação toda que o jogo vai pedir, a busca do conhecimento, a vitória não é só pra você! É pra sociedade! 
Entrevistado 3: E você construiu isso junto com os outros!

Entrevistado 1: É, você vai construir junto!

Em se considerando que situações de risco são ameaças que, normalmente, afligem coletividades, faz sentido o pensamento que os entrevistados desenvolvem acerca do comportamento coletivo dentro do jogo. Sugerem que o jogo trabalhe sob uma perspectiva comportamental altruística, de trabalho coletivo no desempenho das tarefas do jogo, porque sejam os resultados funestos ou benéficos, eles atingirão a maioria. O Entrevistado 5, entusiasmado com o processo, coloca a questão da seguinte maneira:

Entrevistado 5: Pro pessoal agir como equipe, porque, tipo assim, o lixo que eu joguei lá, o problema vai ser só meu? Não!Vai ser da comunidade, de todos! Se dá enchente, é problema pra várias pessoas. Aí a pessoa vai saber ali que não basta ser um, "basta eu fazer minha parte e o resto dane-se pra lá". Quer dizer, todo mundo fazendo uma parte, e junto. Aí vai dar um outro total resultado.

Os depoimentos expõem claramente o sucesso da proposta de utilização do grupo focal no sentido de construção coletiva e partilha de conhecimentos e saberes, para processos de intervenção que se proponham a ser construídos com os sujeitos da pesquisa e não para os objetos de pesquisa. Expusemos aqui somente alguns pequenos trechos para ilustrar a também breve argumentação, mas facilmente pudemos perceber o quanto as pessoas se sentiram afetadas pela participação em todo o processo. Desde aqueles momentos iniciais de exposição e troca de saberes e vivências individuais, até nos instantes finais de discussão sobre como se daria a dinâmica do jogo, que elementos deveriam constar do jogo para que as informações pudessem ser mais bem tratadas e assimiladas pelos futuros usuários.

O jogo foi, portanto, construído baseando-se profundamente na base conceitual teórica que sustenta a sua discussão de riscos, mas também se apoiando nas informações prospectadas no universo empírico, visando à construção de uma simetria entre saberes. A dinâmica do jogo procura tornar o jogador o sujeito do seu próprio aprendizado, que ocorre no contato com os outros jogadores, mediado pelo tabuleiro. Existem ali informações impressas que se misturam às visões de mundo, representações sociais, impressões, vivências, experiências de cada um. No confronto ou na partilha de ideias e conhecimentos, ressignifica-se a própria realidade, descortinam-se novas perspectivas. Ou como diria Paulo Freire, acerca desse processo de problematização, "é a reflexão que alguém exerce sobre um conteúdo, fruto de um ato, ou sobre o próprio ato, para agir melhor, na própria realidade" (FREIRE, 2006:83).

Criar tensão com o racional, ou ainda, problematizar as situações que são vividas, muitas delas já naturalizadas como eventos corriqueiros na vida dos indivíduos, é uma alternativa que parece muito importante, ainda mais quando se pensam em atividades não invasivas ou mecanicistas e heteronômicas, mas que prezem pela autonomia crítica, pela valorização das trocas experienciais, da sinergia social que se pode alcançar na construção social no encontro de múltiplas subjetividades.

O jogo como dimensão da cultura [...] se constitui como produção humana por meio de processos que incorporam valores, saberes, motivações e desejos de cada um dos sujeitos, atribuindo sentidos e significados às diferentes experiências. Toda e qualquer produção cultural, na sua dimensão estética, simbólica e prática, pode agregar diferentes funções sociais (ISAYAMA e VIANA, 2012:124).

Dessa forma, o jogo construído a que se refere este relato, coloca-se, primeiramente, como um instrumento lúdico informativo, mas, também, e talvez o mais importante, seja a sua dupla natureza no que diz respeito à construção coletiva do conhecimento. Isto é, no processo de elaboração do jogo foram utilizadas 
informações extraídas dos pilotis teóricos de sustentação deste estudo e das experiências compartilhadas nos grupos focais e, além disso, mesmo a dinâmica, regras e elementos constituintes foram discutidos com os entrevistados, numa primeira construção social. Emergiu das reuniões aquilo que veio a se tornar a sua segunda natureza de construção social do conhecimento, inerente ao fator colaborativo do compartilhamento dos saberes para se avançar no jogo: o debate, a troca de experiências, as múltiplas narrativas são exigências para o desenrolar dinâmico do jogo. O jogo coloca-se, dessa forma, acima de tudo, como um catalisador para discussões, pois o espaço, a comunidade, o meio, são produtos das práticas sociais que permitem a produção e a reprodução da vida social e, portanto, devem ser considerados, pensados, problematizados, também por uma perspectiva participativa.

\section{CONSIDERAÇões FINAIS}

O homem, como diria Paulo Freire (2007), só se educa no contato com o outro. Adquirimos nosso caráter humano a partir do momento em que conseguimos reconhecer e significar aquilo que nos cerca. Esses significados são construções sociais oriundas das relações de troca e dos vínculos que estabelecemos durante a vida, e é nessa esfera que nos instrumentalizamos para transformarmos a nossa realidade.

Tentamos apresentar aqui a utilização de processos participativos na construção de um instrumental lúdico para a educação ambiental, no sentido de tornar o processo mais legítimo e exequível, exatamente por ser uma proposta de produção coletiva, na qual a dinâmica é construída com as pessoas, e não apenas para as pessoas. Especificamente tratamos da utilização do grupo focal como uma metodologia de prospecção de subsídios para a construção de um jogo que auxilie na percepção de riscos, através do abalizamento do olhar. Sua ancoragem na educação ambiental é fundamental nesse processo, por considerar o homem não dissociado do meio natural; ela pretende levar a processos de geração de autonomia através do processo de ressignificação das esferas objetivas da vida, dentre elas os problemas socioambientais.

Nesse sentido, abordar a temática dos riscos através de um instrumento lúdico ancorado em princípios da educação ambiental, num momento em que as consequências da modernidade avolumam-se sobre os atores individuais e coletivos, parece ser uma alternativa assaz relevante, na medida em que a proposta escapa das tradicionais abordagens heteronômicas, que desconsideram o sujeito humano fora da sua construção. Os jogos se mostram bastantes eficazes no sentido de abordar os mais diversos temas junto a sujeitos dos mais diversos extratos etários e fases do desenvolvimento cognitivo, e isso vem sendo explorado de forma significativa. A inovação da nossa proposta é, especificamente, a elaboração do recurso lúdico como algo construído de forma polissêmica com os sujeitos, de modo a gerar um instrumento que seja plástico, adaptável a cada situação. Além disso, o jogo contará também com a participação dos jogadores, não no sentido de seguir estritamente aquilo que está proposto em suas regras, mas com a participação objetiva e a discussão da realidade de cada um diante dos riscos como determinante do progresso da partida.

Assim, ao abordarmos os sujeitos e as temáticas valendo-nos da metodologia do grupo focal, conseguimos significar uma série de conteúdos, e ressignificar uns tantos outros, e mais, conseguimos, no confronto das ideias, das crenças, valores, representações de cada um, gerar um conhecimento prático sobre riscos, que pode ser aproveitado no jogo como exemplificação para o processo de modificação do próprio olhar dos sujeitos jogadores. A técnica metodológica utilizada na prospecção dos dados empíricos foi determinante do sucesso dessa proposta e mais: seu caráter de estimular a exposição e a discussão das ideias foi destacado pelos próprios participantes das reuniões como um elemento fundamental na construção da própria dinâmica do jogo.

Compreendemos que qualquer ser humano é capaz de intervir na melhoria da sua própria realidade, de fazer modificações profundas em sua vida objetiva e mesmo no meio em que está inserido. Portanto, não 
pretendemos, com nossa proposta, substituir a iniciativa de qualquer um, mas propor um instrumental que estimule esse processo que se ancore, sobretudo, no respeito às crenças, aos saberes, às representações e às identidades dos atores envolvidos.

Para além da questão meramente utilitária e instrumental da atividade lúdica, é possível a construção social do conhecimento que virá a ser compartilhado naquele momento mesmo da vivência, através de dinâmicas que realmente envolvam o sujeito nesse processo, valorizando a sua capacidade de problematização reflexiva, de participação solidária, e mesmo de democratização cultural. E mais, quando se procura diminuir a distância entre quem cria e quem utiliza o jogo, como foi o caso descrito no presente estudo, a atividade lúdica torna-se mais bem fundamentada pela realidade empírica daqueles que a utilizarão, isto é, a aproximação com a realidade, a apropriação das questões do meio, torna o processo de problematização reflexiva que se pretende atingir muito mais exequível.

\section{REFERÊNCIAS}

BECK, U. "Momento cosmopolita" da sociedade de risco. Artigo traduzido por Germana Barata e Rodrigo Cunha. Revista eletrônica de jornalismo científico. Com Ciência - SBPC/Labjor, 2008a.

Disponível em: http://www.comciencia.br/ comciencia/?section $=8 \&$ edicao $=41 \&$ id $=501$, acessado em 03/04/2012.

BECK, U. La sociedad del riesgo mundial: en busca de la seguridad perdida. Paidós: Barcelona, Espanha. 2008b. 333p.

BOURDIEU, P. O Poder Simbólico. Rio de Janeiro: Ed. Bertrand Brasil, 1989.

BRASIL. Secretaria de Educação Fundamental. Parâmetros curriculares nacionais: introdução aos parâmetros curriculares nacionais / Secretaria de Educação Fundamental. Brasília:
MEC/SEF, 1997. 126p.

BROTTO, F.O. Jogos cooperativos: se o importante é competir, o fundamental é cooperar! Ed. Re-Novada. Santos, SP: Projeto Cooperação, 1997.

BRÜSEKE, F.J. Risco e contingência. Rev. bras. Ci. Soc. v.22 n.63 São Paulo fev. 2007. Disponível em: http://dx.doi.org/10.1590/S010269092007000100006, acessado em 03/04/2012.

CARTADE BELGRADO, A. Educação ambiental e desenvolvimento: documentos oficiais, Secretaria do Meio Ambiente, Coordenadoria de Educação Ambiental, São Paulo, 1994, Série Documentos, ISSN 0103-264X. Disponível em http:// openlink.br.inter.net/jctyll/1903.htm, acessado em 11 de setembro de 2010.

CASPARRI, M.T., FUSCO, M., FRONTI, V.G. Exposición y percepción del riesgo por parte de los productores agropecuarios. Anais. VII Jornadas Interdisciplinarias de estudiosagrarios y agroindustriales. Buenos Aires, 2011.

\section{COELHO, F.M.G. A arte das orientações}

técnicas no campo: concepções e métodos. Viçosa: Ed. UFV, 2005. 139p.

\section{DIAS, G.F. Atividades interdisciplinares de} educação ambiental: práticas inovadoras de educação ambiental. São Paulo: Gaia, 2006.

\section{DOUGLAS, M.;WILDAVSKY, A. Risco e} cultura: um ensaio sobre a seleção de riscos tecnológicos e ambientais. Traduzido por Cristiana de Assis Serra. Rio de Janeiro: Elsevier, 2012. 205p.

EINLOFT, C.J.; SANTOS, M.M.B.; LANI. J.L.; SOUZA, R.M. Metodologias participativas na sensibilização e transformação da relação do homem com o meio. Anais do XXVIII Congresso 
Internacional da Associação Latino-Americana de Sociologia, 2011. Disponível em http:// www.sistemasmart.com.br/alas/arquivos/ alas_GT15_Carlos_Joaquim_Einloft.pdf.

Acessadoem 15/05/2012.

FRA PALEO, U. El avance de la gestión hacia la gobernaza del riesgo en umconstexto de complejidad e incertidumbre. In: FERREIRA NETO, J.A.; SOUSA, D.N.; MILAGRES, C.S.F. (orgs).

Recursos naturais, sistemas de informação geográfica e processos sociais. Viçosa, MG: UFV; Visconde do Rio Branco: Suprema, 2010a. pp.43-57.

FRA PALEO, U. Incertidumbre em la tierra apacible. Los riesgos naturales en Galicia. In: Fra Paleo, U. (org.). Riesgos naturales em Galicia. El encuentro entre naturaleza y sociedad. Universidade de Santiago de Compostela: Servizo de Publicación e Intercambio Científico. 3ed., 2010b. pp.1-12.

FRA PALEO, U. Información e incertidumbre em la planificación del riesgo. In: FERREIRA NETO, J.A.; EINLOFT, C.J.; GONÇALVES, R.L. (orgs.).

Desenvolvimento rural, sustentabilidade e ordenamento territorial. Viçosa, MG: UFV;

Visconde do Rio Branco: Suprema, 2011. pp.51-60.

FREIRE, P. A educação como prática da liberdade. $31^{\mathrm{a}}$ ed. Rio de Janeiro: Paz e Terra, 2007.

FREIRE, P. Extensão ou comunicação? $13^{\circ}$ ed. Rio de Janeiro: Paz e Terra, 2006.

FREIRE, P. Pedagogia da autonomia: saberes necessários à prática educativa. São Paulo: Paz e Terra, 1996. 146p.

GIDDENS, A. As consequências da modernidade. São Paulo: Editora Unesp, 1991. $177 \mathrm{p}$.
GIDDENS, A.; BECK, U.; LASH, S. Modernização reflexiva: política, tradição e estética na ordem social moderna. São Paulo: Editora Unesp, 1997. 264p.

GUIVANT, J. S., A teoria da sociedade de risco de Ulrich Beck: entre o diagnóstico e a profecia, Rio de Janeiro, Estudos Sociedade e Agricultura, 16, abril 2001. Disponível em http://168.96.200.17/ar/ libros/brasil/cpda/estudos/dezesseis/julia16.htm. Acessado em 03/05/2012.

ISAYAMA, H.F.; VIANA, J.A. Jogos e(m) sociedade: reflexões sobre o campo do lazer. In: CARRIERI, A.P.; GOBIRA, P. Jogos e sociedade: explorando as relações entre jogo e vida. Belo Horizonte: Crisálida, NEOS. 2012. 200p.

LOPES, U. M.; TENÓRIO, R. M. Educação como fundamento da sustentabilidade. Salvador: EDUFBA, 2011. 170p.

LOUREIRO, C.F.B. Teoria crítica. In: BRASIL, Ministério do Meio Ambiente. Encontros e caminhos: formação de educadoras(es) ambientais e coletivos educadores. Luiz Antônio Ferraro Junior (organizador). Brasília: MMA, Diretoria de Educação Ambiental, 2005. 358p.

MINAYO, M.C.S. Análise qualitativa: teoria, passos e fidedignidade. Ciênc. saúde coletiva vol.17. n.3. Rio de Janeiro. Mar. 2012b. pp. 621-626. Disponível em <http://dx.doi.org/10.1590/S1413$81232012000300007>$, acessado em 10/04/2013.

MINAYO, M.C.S., ASSIS, S.G., SOUZA, E.R. Avaliação por triangulação de métodos: abordagem de programas sociais. Rio de Janeiro: Editora Fiocruz, 2010. 244p.

NETO, O.C.; MOREIRA, M.R.; SUCENA, L.F.M. Grupos Focais e Pesquisa Social Qualitativa: o debate orientado como técnica de investigação. 
Associação Brasileira de Estudos Populacionais, Anais..., Núcleo de Estudos Populacionais da Unicamp, SP. 2002. Disponível em http:// www.abep.nepo.unicamp.br/docs/anais/pdf/2002/ Com_JUV_PO27_Neto_texto.pdf, acessado em $15 / 06 / 2012$

ROJAS, J. O lúdico na construção interdisciplinar da aprendizagem: uma pedagogia do afeto e da criatividade na escola. UFMS. Disponível em http://189.1.169.50/reunioes/ 25/excedentes25/jucimararojast07.rtf. Acessado em 24/08/2010.
SACHS, I. Sociedade, cultura e meio ambiente, Rio de Janeiro, Mundo e Vida Social, 2 (1), 2000. Disponível emhttp://www.uff.br/cienciaambiental/mv/ mv1/MV1(1-2)07-13.pdf. Acessado em 11/05/2012.

ZANIRATO, S.H.; RAMIRES, J.Z.S; AMICCI, A.G.N.; RIBEIRO, Z.M. RIBEIRO, W.C. Sentidos do risco: interpretações teóricas. Biblio3W. Revista Bibliográfica de Geografía y CienciasSociales. Serie documental Geo Critica. Universidad de Barcelona, Espanha, vol. XIII, n. . 785, 2008. Disponível em http://www.ub.edu/geocrit/b3w785.htm, acessado em 06/05/2012. 